\title{
Operational Safety Risk Assessment for the Water Channels of the South-to-North Water Diversion Project Based on TODIM-FMEA
}

\author{
Huimin Li $\mathbb{D}^{1},{ }^{1}$ Li Ji $\left(\mathbb{D},{ }^{1}\right.$ Feng Li $\mathbb{D},{ }^{1}$ Hairui Li $\mathbb{D},{ }^{2}$ Qingguo Sun $\left(\mathbb{D},{ }^{3}\right.$ Zhihong Li $\left(\mathbb{D},{ }^{3}\right.$ \\ Hongmei Yan $\left(\mathbb{D},{ }^{3}\right.$ Wei Guan $\mathbb{D}^{\mathrm{D}},,^{3}$ Lunyan Wang $\mathbb{D}^{1,4,5}$ and Ying Ma $\mathbb{D}^{1,4}$ \\ ${ }^{1}$ Department of Construction Engineering and Management, North China University of Water Resources and Electric Power, \\ Zhengzhou 450046, China \\ ${ }^{2}$ School of Management and Economics, North China University of Water Resources and Electric Power, \\ Zhengzhou 450046, China \\ ${ }^{3}$ Bureau of South to North Water Transfer of Planning, Design and Management, Ministry of Water Resources, \\ Beijing 100038, China \\ ${ }^{4}$ Henan Key Laboratory of Water Environment Simulation and Treatment, Zhengzhou 450045, China \\ ${ }^{5}$ Collaborative Innovation Center of Water Resources Efficient Utilization and Protection Engineering, Zhengzhou 450045, China \\ Correspondence should be addressed to Feng Li; lifeng9406@126.com
}

Received 26 October 2020; Revised 26 November 2020; Accepted 30 November 2020; Published 12 December 2020

Academic Editor: Shi Cheng

Copyright (c) 2020 Huimin Li et al. This is an open access article distributed under the Creative Commons Attribution License, which permits unrestricted use, distribution, and reproduction in any medium, provided the original work is properly cited.

\begin{abstract}
The South-to-North Water Diversion Project consists of long-distance water delivery channels and a complicated geological environment along the way. To deal with the operation safety of the water conveyance channels in the middle route of the Southto-North Water Diversion Project, this study analyzes six failure modes: structural cracks, poor water delivery during ice periods, instability of canal slopes, material aging, abnormal leakage, and foundation defects. Based on FMEA, a multigranularity language evaluation method that can be converted into interval intuitionistic fuzzy numbers is used to evaluate the severity $(S)$, occurrence $(O)$, and detection difficulty $(D)$ of the six failure modes. Interval intuitionistic fuzzy entropy is used to calculate the weights of the risk factors. Finally, a ranking model of each failure mode is built based on the TODIM method. The final ranking results show that the risk of abnormal leakage is the largest, and the risk of poor water delivery during ice periods is the smallest. The feasibility and validity of the calculation results are verified by comparing them with the ranking results of the traditional RPN and TOPSIS methods. The TODIM-FMEA risk assessment model offers a new solution to the problem of risk assessment for water transfer projects.
\end{abstract}

\section{Introduction}

The South-to-North Water Diversion Project (SNWDP), also called the South-North Water Transfer Project, is an ongoing Chinese effort to channel 45 billion $\mathrm{m}^{3}$ of water annually from the Yangtze River in southern China to the country's less-fertile northern regions [1]. The SNWDP consists of three water diversion projects, the East Route Project (ERP), the Middle Route Project (MRP), and the West Route Project (WRP), which divert water from the lower, middle, and upper reaches of the Yangtze River, respectively, as shown in Figure 1. Both Phase I of the ERP and Phase I of the MRP have been in operation since 2013 and 2014, respectively [2]. The $1432 \mathrm{~km}$ MRP diverts water from the Danjiangkou Reservoir in the Hanjiang River basin to 20 major cities and 100 counties in Henan and Hebei provinces, Beijing, and Tianjin municipalities [3]. There are complex hydraulic structures in the long channel, and MRP provides drinking water in an open/ covered channel to Beijing and Tianjin under extremely strict water quality requirements, all of which pose a significant challenge $[4,5]$. The average annual water supply capacity of the MRP is 9.5 billion cubic meters [6]. The MRP mainly comprises open channels for water 


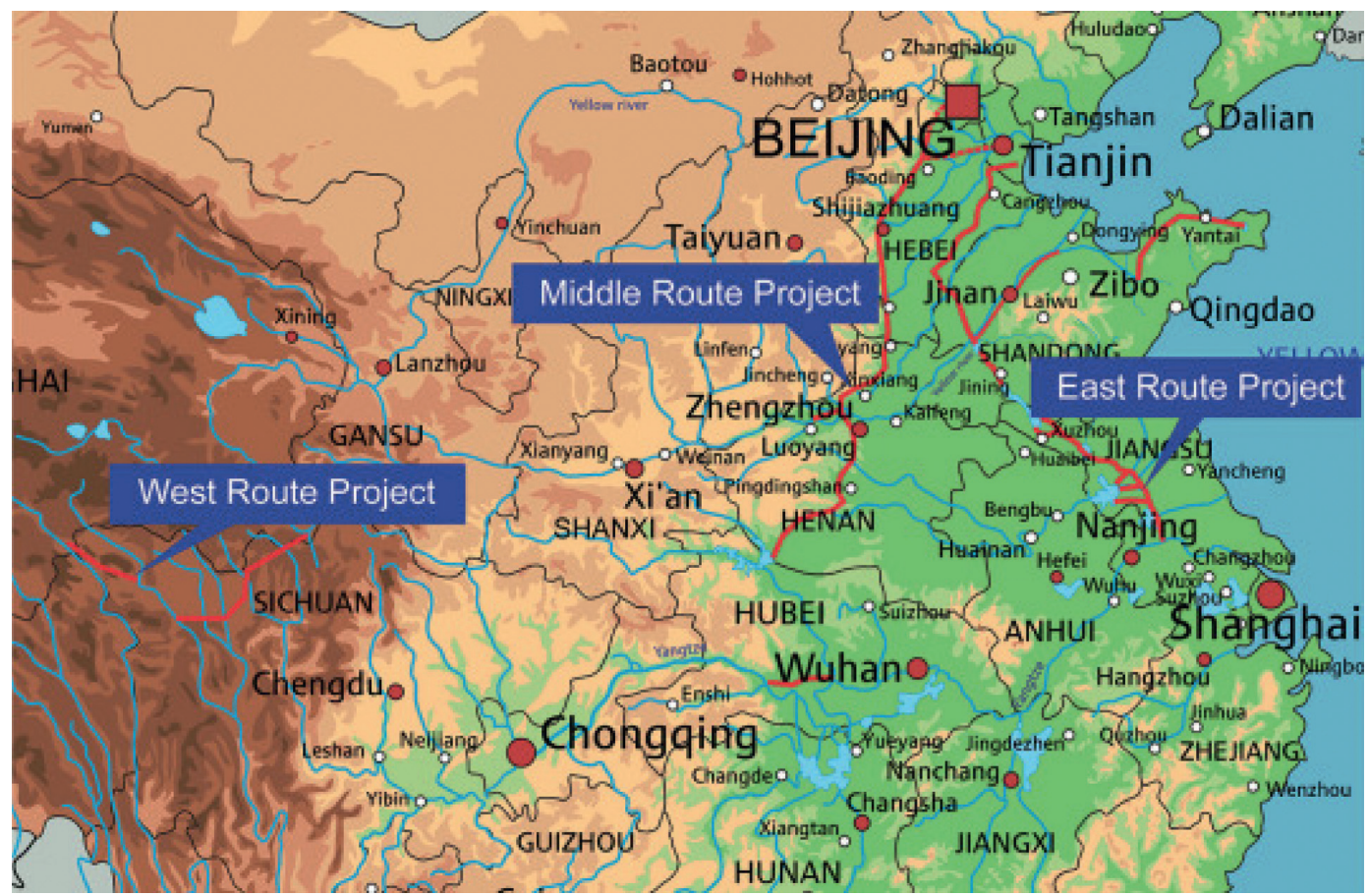

FIgUre 1: The three routes of the South-to-North Water Diversion Project.

conveyance, and the complex geological conditions and natural environment along the route make the potential operation risks very complex and difficult to grasp. In order to effectively control the operation risks, ensure the water diversion system can operate safely, efficiently, and scientifically, and maximize the benefits of the project, it is necessary to carry out risk identification and risk assessment in advance.

Many scholars have conducted extensive research on the operation risk of the South-to-North Water Diversion Project. Du and Geng [7] adopted risk projection graphs to predict and analyze the engineering risks of the water conveyance channels in the MRP and used failure probabilities and grades of failure consequences to evaluate the risks of each engineering section of the water conveyance channels in the MRP. Hu et al. [8] summarized the operation risk evaluation indices of open water channels and obtained risk grades by using right-angle fuzzy sets and the Technique for Order Preference by Similarity to Ideal Solution (TOPSIS) [9]. Zhou et al. [10] put forward a plan and management measures for dispatching water during ice periods and formulated an emergency plan and early warning forecast for ice periods. Cheng et al. [9] believed that the water diversion project is a long line series system and calculated the system reliability indices of the three typical modes of failure, i.e., overtopping, seepage failure, and landslide of channel slope failures in the MRP, by approximately reconstructing a linear system safety margin equation. Xiong et al. [11] classified and summarized the failure modes of different hydraulic structures in the MRP. To sum up, the risk analysis studies of typical hydraulic structures in the MRP have been widely carried out, but most of them are qualitative analyses or quantitative evaluations of specific failure modes of typical hydraulic structures.
Failure Mode and Effects Analysis (FMEA) is a widely used method for analyzing system reliability and risk management in various fields, such as automotive, manufacturing, chemical, and engineering [12-14]. Traditional FMEA multiplies the three risk factors, i.e., severity $(S)$, occurrence $(O)$, and detection difficulty $(D)$, to obtain the risk priority number (RPN) and then ranks the identified failure modes [12]. Although the traditional FMEA method has the advantages of ease of use and versatility, there are still many defects. Many scholars have used different methods to improve the FMEA method to make the results more reasonable. Chang [15] introduced binary semantic variables to assess the failure mode information. Vahdani et al. [16] proposed a FMEA method based on the fuzzy belief structure representation. Wang et al. [17] improved the FMEA method by using language variables convertible to intuitionistic fuzzy numbers to represent information regarding failure modes and the weight of the risk factors. These scholars resolved the shortcoming of the traditional FMEA method, which was the difficulty of representing failure mode information directly using real numbers.

Other scholars have resolved another defect of the traditional FMEA method, which is its failure to account for the weight information of the risk factors. Emovon et al. [18] proposed an objective weighting method based on a synthesis of the variance method and entropy weight method. Zhu et al. [19] used the TOPSIS method to build an optimization model of risk factor weights. Many scholars introduced multicriteria decision-making methods to improve FMEA. Liu et al. [20] proposed a method based on intuitionistic fuzzy numbers and TOPSIS to improve the sorting of failure modes in FMEA. Chang et al. [21] considered the correlation between failure modes and proposed a FMEA 
risk assessment method based on Decision-Making Trial and Evaluation Laboratory (DEMATEL) and TOPSIS. These methods resolved the problem with traditional RPN value results, that is, identical risk priority values may be obtained, which make failure mode risk ranking unworkable. The interactive multicriteria decision-making method (Tomada de Decisão Interativa Multicritério, TODIM) is a multicriteria decision-making method based on the prospect theory proposed by Gomes and Lima [22]. In this method, the psychological behaviors of decision makers are taken into full consideration, and alternatives are ranked according to the relative dominance of one alternative over other alternatives.

However, it should be pointed out that there are still the following problems with the existing studies: (1) the existing information assessment methods adopted by representation experts are useful in characterizing the fuzziness and uncertainty of the information, but they fail to consider the certainty level, uncertainty level, and hesitation level simultaneously; (2) the existing multicriteria decision-making methods resolve the problem with the traditional methods, that is, identical RPN values, which make ranking unworkable, but they neglect the influence of the psychological behaviors of different experts on the risk ranking results.

In order to overcome the shortcomings of FMEA, in this paper, multigranularity language information is converted into interval intuitionistic fuzzy numbers to represent the failure modes. The weights of risk factors are calculated using improved interval intuitionistic fuzzy entropy, which has been adapted to a TODIM-based FMEA method to rank the failure modes. The improved FMEA method is applied to assess operation safety risks of the MRP.

The remainder of the paper is organized as follows. Section 2 presents operation risks and failure modes of the water channels in the MRP. Section 3 introduces the research methods: a TODIM-FMEA risk evaluation method based on multigranularity language information. A case study is presented in Section 4. Finally, conclusions and recommendations are drawn in Section 5.

\section{Failure Modes of the Water Channels in the MRP}

The majority of the open water channels in the MRP is made of lined concrete structures, and lined concrete structures have the characteristics of being thin and having large surface areas, as shown in Figure 2. The distance along the channels is quite long, and the channels pass through high embankments, deep excavations, and expansive soil treatment sections. The water channels are highly exposed to the natural environment and human activities, which make the operation safety risks more complex than they are in any other channels. Based on an analysis of the risk factors in the literature [7-11] and on the opinions of practical experts on the MRP, this paper has chosen the six most typical failure modes of the water conveyance channels. The failure modes include structural cracks (FM1), poor water delivery during ice periods (FM2), instability of canal slopes (FM3), material aging (FM4), abnormal leakage (FM5), and foundation

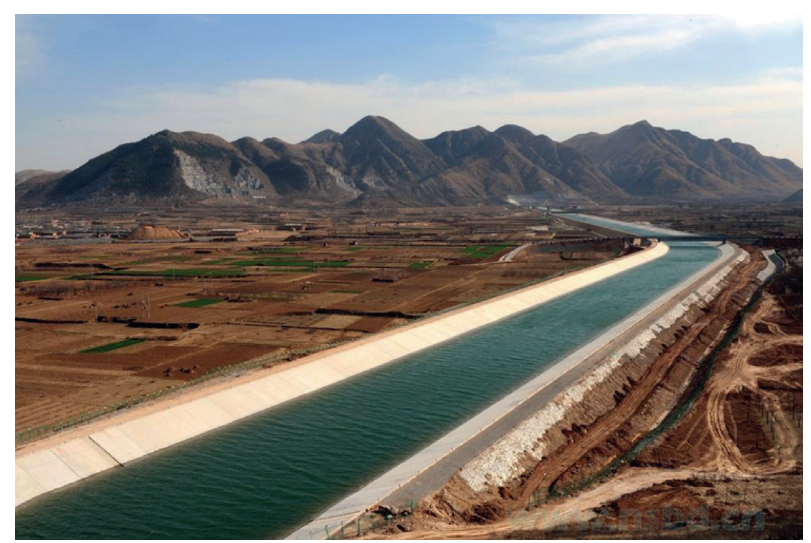

Figure 2: Water channel of the middle route of the South-to-North Water Diversion Project.

defects (FM6). The main causes and failure consequences of the six failure modes are shown in Table 1.

2.1. Structural Cracks (FM1). Cracks are common in concrete structures, and they are caused by the interaction between the concrete and the external environment. The fundamental reason for cracks is when structural stress exceeds the tensile strength of the concrete materials. Cracks often appear in various structures. When a crack is not serious, it will not affect the normal operation of the project, but cracks accelerate the aging of the concrete and reduce the structure's ability to resist freeze-thaw damage and environmental erosion damage. In channel engineering, cracks have very limited effect on structures when they appear initially, but if no measures are taken to prevent the cracks from expanding, they will cause leakage and serious damage to the lining of the structures.

\subsection{Poor Water Delivery during Ice Periods (FM2).}

Almost half of the MRP is in the northern part of China, where the winter temperatures are always below zero degrees centigrade, and the channels thus deliver water with ice. The shape of the cross sections of the channels through which water flows is an inverted trapezoid, and the cross sections may be affected by the flowing ice and ice jams. The phenomenon of backwater may form due to ice jams, increasing the danger of water overtopping the embankments. During ice periods, it is also possible that the ice slag mixed with floating grass may endanger the safe operation of the water delivery system. During ice periods, the variation of the water level should be strictly controlled, and the water flow should be reduced properly to keep the flow rate at a low level.

2.3. Instability of the Channel Slope (FM3). The causes of channel instability risks mainly include foundation conditions and environment conditions. Foundation conditions primarily refer to the geological conditions of the terrain through which the channels pass. If there are unstable properties and weak intercalations in the foundation, the 
TABLE 1: The failure modes of the water channels in the MRP during the operation stage.

\begin{tabular}{|c|c|c|c|}
\hline $\begin{array}{l}\text { Serial } \\
\text { number }\end{array}$ & Failure mode & Main causes of the failure & Effects of the failure \\
\hline FM1 & Structural cracks & $\begin{array}{l}\text { Temperature change, shrinkage, freezing, } \\
\text { uneven settling of the foundation, etc. }\end{array}$ & $\begin{array}{c}\text { Reduce the durability of the structure, weaken its bearing } \\
\text { capacity, and can cause failure and destruction of the } \\
\text { structures }\end{array}$ \\
\hline FM2 & $\begin{array}{l}\text { Poor water delivery } \\
\text { during ice periods }\end{array}$ & Ice blocks the water delivery & Water overflows and damage to channel embankments \\
\hline FM3 & $\begin{array}{l}\text { Instability of the } \\
\text { channel slope }\end{array}$ & $\begin{array}{l}\text { Sudden change of water } \\
\text { the antislide stability }\end{array}$ & $\begin{array}{l}\text { Causes overtopping and regional floods around the water } \\
\text { diversion system }\end{array}$ \\
\hline FM4 & Material aging & $\begin{array}{l}\text { Carbonization of concrete, temperature } \\
\text { change, and freeze-thaw damage }\end{array}$ & 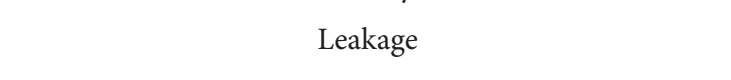 \\
\hline FM5 & Abnormal leakage & and biological destruction & $\begin{array}{c}\text { The collapse of the bank slope, which affects the safety of } \\
\text { the structures }\end{array}$ \\
\hline FM6 & Foundation defects & $\begin{array}{l}\text { Expansive (rock) soils, loess soil, saturated } \\
\text { sand sections, and filled sections }\end{array}$ & $\begin{array}{l}\text { Loss of bearing capacity of the foundation and collapse of } \\
\text { structures }\end{array}$ \\
\hline
\end{tabular}

Note. FM: failure mode.

channels will be prone to instability and deformation. Environment conditions primarily refer to earthquakes, torrential rain, flooding, snowmelt, and sudden changes in the water level. These environmental factors affect the stress state of the embankment and cause instability of the channel slope.

2.4. Material Aging (FM4). Material aging is a common phenomenon in water conservancy projects. The chief causes of material aging are concrete carbonization, temperature changes, and freeze-thaw damage. Firstly, carbonization occurs when the alkaline material in concrete reacts with $\mathrm{CO}_{2}$, producing carbonate and water, and this process will reduce the strength of the concrete. Carbonization causes the protective layers to deteriorate and steel bars to corrode, which further weakens the strength of the concrete. Secondly, temperature changes cause the shrinkage of concrete and uneven subsidence, which lead to cracks in the concrete. Finally, freeze-thaw damage is typically manifested in the shedding and cracking of the concrete lining of the channels, which leads to serious water leakage.

2.5. Abnormal Leakage (FM5). The embankment of the MRP is made of soil, so leakage from the channels erodes the foundation, endangering the overall stability of the channel structure. In water conservancy projects, the dryness and wetness of the environment take effect alternately, which leads to the concrete alternating between shrinkage and expansion and produces microcracks. The expansion and penetration of microcracks lead to significant seepage from the concrete. In addition, uneven subsidence deformation and biological damage cause cracks. For instance, mice or termite nests will also directly cause water seepage, piping, and, at worst, subsidence.

2.6. Foundation Defects (FM6). The MRP consists of expansive rock, expansive soil, loessial soil, saturated sand, and filled sections. One characteristic of expansive soil is that it expands when encountering water and shrinks when losing water. The presence of expansive soil causes the channels to crack, tilt, and even be destroyed. Most loessial soil is collapsible when it encounters water, which results in the subsidence of the channel foundation and slopes. Saturated sand always creates the problem of liquefaction. Liquefaction reduces the bearing capacity of the foundation, eventually causing the structures to subside and collapse. In the filled section of the channel, if the filling is not compacted, it results in instability and leakage.

\section{Research Method}

In this study, a multigranularity linguistic evaluation method that can be converted into interval intuitionistic fuzzy numbers is used to evaluate the severity $(S)$, occurrence $(O)$, and detection difficulty $(D)$ in FMEA. Interval intuitionistic fuzzy entropy is used to calculate risk factor weights. And, finally, a ranking model of each failure mode is built based on the TODIM method.

\subsection{Risk Expression Based on Multigranularity Language Information Convertible to Interval Intuitionistic Fuzzy Numbers}

\subsubsection{Multigranularity Language Information}

Definition 1. The multigranularity language assessment set is denoted as

$$
S^{q}=\left\{s_{i}^{q}|i \in|\left\{-\frac{q-1}{2}, \ldots,-1,0,1, \ldots, \frac{q-1}{2}\right\}\right\} .
$$

In the formula, $S_{i}^{q}$ indicates the $i$ evaluation phrase of $S^{q}$, and $q$ must be odd. When $q=5$, the evaluation phrase set $S^{q}$ is denoted as $\{$ very bad, bad, average, good, very good\}.

Generally, the properties of $S_{i}^{q}$ should meet the following requirements:

(1) Order: when $i \geq j, s_{i}^{q} \geq s_{j}^{q}$

(2) Inverse operator: when $j=q-1, \operatorname{Neg}\left(s_{i}^{q}\right)=s_{i}^{q}$

(3) Maximum operation: if $s_{i}^{q} \geq s_{i}^{q}$, then $\max \left(s_{i}^{q}, s_{j}^{q}\right)=s_{i}^{q}$ 
(4) Minimal operation: if $s_{i}^{q} \leq s_{i}^{q}$, then $\max \left(s_{i}^{q}, s_{j}^{q}\right)=s_{i}^{q}$

\subsubsection{Intuitionistic Fuzzy Sets}

Definition 2 (see [23]). $X$ is a nonempty set, $X=\left\{x_{1}, x_{2}, \ldots, x_{n}\right\}$, and, on $X$, each of those like $\left.A=\left\{\left\langle x, \mu_{A}(x), v_{A}(x)\right\rangle \mid x \in X\right\}\right\}$ is called an intuitionistic fuzzy set on $X$, where $\mu_{A}(x)$ and $\nu_{A}(x)$ are the membership grade and nonmembership grade of element $x$ belonging to judgment set $A$, where $\mu_{A}(x): X \longrightarrow[0,1], \quad v_{A}(x)$ : $X \longrightarrow[0,1]$, and $0 \leq \mu_{A}(x)+\nu_{A}(x) \leq 1, x \in X$.

In addition, $\pi_{A}(x)=1-\mu_{A}(x)-v_{A}(x)$ indicates the hesitancy degree of the element $x$ belonging to $A$, where $0 \leq \pi_{A}(x) \leq 1, x \in X$.

Definition 3 (see [24]). When $X$ is set as a nonempty set, $X=\left\{x_{1}, x_{2}, \ldots, x_{n}\right\}$, then an interval intuitionistic fuzzy set on $X$ is defined as $\widetilde{A}=\left\{\left\langle x, \mu_{\tilde{A}}(x), \nu_{\tilde{A}}(x)\right\rangle \mid x \in X\right\}$, where $\mu_{\tilde{A}}: X \longrightarrow[0,1]$ and $\nu_{\tilde{A}}: X \stackrel{\{}{\longrightarrow}[0,1]$, and for all $x \in X$, meets $0 \leq \mu_{\tilde{A}}(x)+\nu_{\tilde{A}}(x) \leq 1$. Interval number $\mu_{\tilde{A}}(x)$ and interval number $v_{\tilde{A}}(x)$ indicate the membership grade and nonmembership grade of element $x$ belonging to $A$, respectively.

In addition, $\pi_{\widetilde{A}}(x)=1-\mu_{\tilde{A}}(x)-\nu_{\tilde{A}}(x)$, which is called the intuition index of the element $x$ in $A$, which is the intuitionistic fuzzy set, indicates the hesitancy degree of the element $x$ belonging to $\widetilde{A}$, where $0 \leq \pi_{\tilde{A}}(x) \leq 1, x \in X$. For each $x \in X, \mu_{\tilde{A}}(x)$ and $\nu_{\tilde{A}}(x)$ are closed interval numbers, and their lower bound and the upper bound are denoted as $\mu_{\sim}^{L}(x), \mu_{\sim}^{U}(x), \nu_{\sim}^{L}(x)$, and $\nu_{\sim}^{U}(x)$, respectively.

For convenience, the intuitionistic fuzzy set $A$ can be denoted as

$$
\widetilde{A}=\left\{\left\langle x,\left[\mu_{\tilde{A}}^{L}(x), \mu_{\tilde{A}}^{L}(x)\right],\left[\nu_{\tilde{A}}^{\frac{L}{L}}(x), \nu_{\tilde{A}}^{\frac{L}{2}}(x)\right]\right\rangle \mid x \in X\right\},
$$

where $0 \leq \mu_{\tilde{A}}^{U}(x)+\nu_{\tilde{A}}^{U}(x) \leq 1,0 \leq \mu_{\tilde{A}}^{L}(x) \leq \mu_{\tilde{A}}^{L}(x) \leq 1$, and $0 \leq$ $\nu_{\widetilde{A}}^{L}(x) \leq \nu_{\widetilde{A}}^{U}(x) \leq 1$. In addition, $\pi_{\widetilde{A}}(x)=1-\mu_{\widetilde{A}}(x)-\nu_{\widetilde{A}}(x)=$ $\left[1-\mu_{\tilde{A}}^{U}(x)-v_{\tilde{A}}^{U}(x), 1-\mu_{\tilde{A}}^{L}(x)-\nu_{\tilde{A}}^{L}(x)\right]$.

Definition 4 (see [25]). Set $\left.\widetilde{A}=\left(a_{1}, a_{2}\right],\left[a_{3}, a_{4}\right]\right)$ as an interval intuitionistic fuzzy number; then, $S(\widetilde{A})=\left(a_{1}-a_{2}+\right.$ $\left.a_{3}-a_{4}\right) / 2$ is called the score function of the interval intuitionistic fuzziness.

Set $\left.\widetilde{A}=\left(a_{1}, a_{2}\right],\left[a_{3}, a_{4}\right]\right)$ and $\left.\widetilde{B}=\left(b_{1}, b_{2}\right],\left[b_{3}, b_{4}\right]\right)$ as two interval intuitionistic fuzzy numbers: if $S(\widetilde{A})<S(\widetilde{B})$, then $\widetilde{A}<\widetilde{B}$.

\subsubsection{Convert Multigranularity Language Phrases into In- terval Intuitionistic Fuzzy Numbers}

Definition 5. Set $S^{q}=\left\{s_{i}^{q}|i \in|\{-(q-1) / 2, \ldots,-1,0,1, \ldots\right.$, $(q-1) / 2\}\}$ as a language evaluation set; $s_{i}^{q}$ is inside $S^{q}$ and can be converted into interval intuitionistic fuzzy numbers as

$$
S^{q}=\left\{\left(\widetilde{\mu}_{i}^{q}, \widetilde{v}_{i}^{q}\right)|i \in|\left\{-\frac{q-1}{2}, \ldots,-1,0,1, \ldots, \frac{q-1}{2}\right\}\right\},
$$

where

$$
\begin{aligned}
& \tilde{\mu}_{i}^{q}= \begin{cases}\left(\widetilde{\mu}_{0}^{q}\right)^{1-i}, & i<0, \\
\left(\widetilde{\mu}_{0}^{q}\right)^{\frac{1}{1+i},}, \quad i \geq 0\end{cases} \\
& \widetilde{\nu}_{i}^{q}= \begin{cases}1-\left(1-\widetilde{\nu}_{0}^{q}\right)^{1-i}, & i<0, \\
1-\left(1-\widetilde{\nu}_{0}^{q} \frac{1}{1+i},\right. & i \geq 0,\end{cases} \\
& \tilde{\mu}_{0}^{q}=\widetilde{v}_{0}^{q}=\left[0.5-\frac{1}{2 q}, 0.5\right] .
\end{aligned}
$$

There are many ways to calculate the distance between interval intuitionistic fuzzy numbers. This paper adopts a new distance formula by combining the two traditional distance measurement formulas, i.e., Hamming distance and Hausdorff distance. The formula combines the advantages of the two distance measures, defined as follows.

Definition 6. Set $\widetilde{A}=\left\{\left\langle x,\left[\mu_{\widetilde{A}}^{L}(x), \mu_{\widetilde{A}}^{U}(x)\right],\left[\nu_{\widetilde{A}}^{L}(x), v_{\widetilde{A}}^{U}(x)\right]\right.\right.$ \rangle $\mid x \in X\}, \widetilde{B}=\left\{\left\langle x,\left[\mu_{\widetilde{B}}^{L}(x), \mu_{\widetilde{B}}^{U}(x)\right],\left[\nu_{\widetilde{B}}^{L}(x), \nu_{\widetilde{B}}^{\mathcal{A}}(x)\right]\right\rangle \mid x \in\right.$ $X\}$, and $\widetilde{C}=\left\{\left\langle x,\left[\mu_{\widetilde{C}}^{L}(x), \mu_{\widetilde{C}}^{U}(x)\right],\left[\nu_{\widetilde{C}}^{L}(x), \nu_{\widetilde{C}}^{U}(x)\right]\right\rangle \mid x \in X\right\}$ as three IVIFNs; then, the distance between $\widetilde{A}$ and $\widetilde{B}$ is defined as

$$
\begin{aligned}
& d(\widetilde{A}, \widetilde{B})=\frac{1}{8} \sum_{i=1}^{n}\left(\left|\mu_{\widetilde{A}}^{\frac{L}{(}}\left(x_{i}\right)-\mu_{\widetilde{B}}^{L}\left(x_{i}\right)\right|+\left|\mu_{\widetilde{A}}^{U}\left(x_{i}\right)-\mu_{\widetilde{B}}^{U}\left(x_{i}\right)\right|\right. \\
& +\left|v_{\tilde{A}}^{L}\left(x_{i}\right)-v_{\widetilde{B}}^{L}\left(x_{i}\right)\right|+\left|v_{\widetilde{A}}^{U}\left(x_{i}\right)-v_{\widetilde{B}}^{U}\left(x_{i}\right)\right| \\
& \left.+\left|\pi_{\widetilde{A}}^{L}\left(x_{i}\right)-\pi_{\tilde{B}}^{L}\left(x_{i}\right)\right|+\left|\pi_{\tilde{A}}^{U}\left(x_{i}\right)-\pi_{\widetilde{B}}^{U}\left(x_{i}\right)\right|\right) \\
& +\frac{1}{2} \sum_{i=1}^{n}\left(\operatorname { m a x } \left(\left|\mu_{\tilde{A}}^{L}\left(x_{i}\right)-\mu_{B}^{L}\left(x_{i}\right)\right|,\left|\mu_{A}^{U}\left(x_{i}\right)-\mu_{B}^{U}\left(x_{i}\right)\right|,\right.\right. \\
& \left|\nu_{\tilde{A}}^{L}\left(x_{i}\right)-v_{B}^{L}\left(x_{i}\right)\right|,\left|v_{\widetilde{A}}^{U}\left(x_{i}\right)-v_{\tilde{B}}^{U}\left(x_{i}\right)\right|, \\
& \left.\left|\pi_{\tilde{A}}^{L}\left(x_{i}\right)-\pi_{\tilde{B}}^{L}\left(x_{i}\right)\right|,\left|\pi_{\tilde{A}}^{U}\left(x_{i}\right)-\pi_{\tilde{B}}^{U}\left(x_{i}\right)\right|\right),
\end{aligned}
$$

where $\pi_{\widetilde{A}}^{L}\left(x_{i}\right)=1-\mu_{\widetilde{A}}^{U}\left(x_{i}\right)-\nu_{\widetilde{A}}^{U}\left(x_{i}\right), \pi_{\widetilde{A}}^{U}\left(x_{i}\right)=1-\mu_{\widetilde{A}}^{L}\left(x_{i}\right)-$ $v_{\widetilde{A}}^{L}\left(x_{i}\right), \quad \pi_{\widetilde{B}}^{L}\left(x_{i}\right)=1-\mu_{\tilde{B}}^{U}\left(x_{i}\right)-\nu_{\widetilde{B}}^{U}\left(x_{i}\right)$, and $\pi_{\widetilde{B}}^{U}\left(x_{i}\right)=1-$ $\mu_{B}^{L}\left(x_{i}\right)-v_{\tilde{B}}^{L}\left(x_{i}\right)$.

3.2. TODIM-FMEA Risk Assessment Method Based on Multigranularity Language Information. The TODIM-FMEA risk assessment model based on multigranularity language information consists of three steps.

(1) FMEA risk assessment experts identify the failure modes and assess the risk factors of the water channels in the MRP. (2) The weights of risk factors $S, O$, and $D$ are 
calculated using interval intuitionistic fuzzy entropy. (3) The interval intuitionistic fuzzy TODIM method is used to rank the risk degrees of the failure modes. The framework of the proposed FMEA model is shown in Figure 3.

In the actual assessment process, information related to failure modes has great uncertainty and incompleteness; therefore, experts must refer to historical data about water channels actually in the MRP to evaluate failure modes. Experts use language variables to express the evaluation information. Then, the language variables are converted into interval intuitionistic fuzzy sets to carry out the calculations. The proposed FMEA model steps are as follows:

Step 1: the expert scoring team comprises $s$ experts $E_{k}(k=1,2, \ldots, s)$, and different weights are assigned to them based on their level of expertise. The risk evaluation process will focus on $m$ potential failure modes $\mathrm{FM}_{i}(i=1,2, \ldots, m)$ of the three risk factors, i.e., severity $(S)$, occurrence $(O)$, and detection $(D)$. The assessment of the three risk factors is presented by multigranularity language information, and then the language variable assessment matrix $X=\left[x_{i j}\right]_{m \times n}$ is determined. The evaluation results should be converted into the corresponding interval intuitionistic fuzzy numbers, where $R=\left[a_{i j}\right]_{m \times n}$ indicates the failure mode interval intuitionistic fuzzy evaluation matrix given by the $s^{\text {th }}$ expert. Based on the weight assigned to the experts and the interval-valued intuitionistic fuzzy weighted arithmetic averaging (IIWAA) operator, the interval intuitionistic fuzzy evaluation matrix is converted into the group integrated weighted intervalvalued intuitionistic fuzzy judgment matrix, which is $R^{\prime}=\left[a_{i j}\right]_{m \times n}$.

Definition 7 (see [26]). Set $\widetilde{\alpha}_{j}=\left(\left[\tilde{a}_{j}, \widetilde{b}_{j}\right]_{j},\left[\widetilde{c}_{j}, \widetilde{d}_{j}\right]\right)$ as the interval intuitionistic fuzzy numbers, $j=1,2, \ldots, n$, and IIWAA: $\Omega^{n} \longrightarrow \Omega$ if

$$
\operatorname{IIWAA}_{\omega}\left(\widetilde{\alpha}_{1}, \widetilde{\alpha}_{2}, \ldots, \widetilde{\alpha}_{n}\right)=\sum_{j=1}^{n} \omega_{j} \alpha_{j}=\left\langle\left[1-\prod_{j=1}^{n}\left(1-a_{j}\right) \omega_{j}, 1-\prod_{j=1}^{n}\left(1-b_{j}\right) \omega_{j}\right],\left[\prod_{j=1}^{n} c_{j} \omega_{j}, \prod_{j=1}^{n} d_{j} \omega_{j}\right]\right\rangle,
$$

where $\omega=\left(\omega_{1}, \omega_{2}, \ldots, \omega_{n}\right)$ are weight vectors and $\omega_{j} \in[0,1], \sum_{j=1}^{n} \omega_{j}=1$; then, we call IIWAA the weighted arithmetic integration operator of the interval-valued intuitionistic numbers.

Step 2: use improved interval intuitionistic fuzzy entropy to calculate the weights and relative weights of risk factors $S, O$, and $D$.
Definition 8. For any interval intuitionistic fuzzy set $\widetilde{A} \in \operatorname{IVIFS} s(X), \forall x \in X$, its entropy is

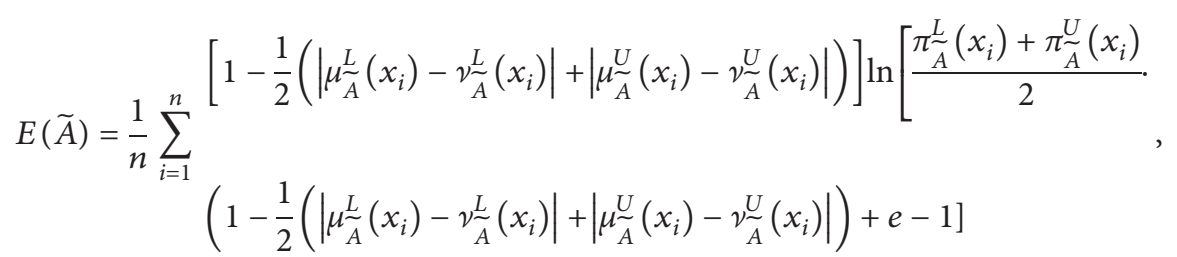

where $\quad\left(1-(1 / 2)\left(\left|\mu_{\sim}^{L}\left(x_{i}\right)-v_{\sim}^{L}\left(x_{i}\right)\right|+\mid \mu \underset{\sim}{U}\left(x_{i}\right)-v_{\frac{U}{A}}^{U}\right.\right.$ $\left.\left(x_{i}\right) \mid\right)$ is the level of information insufficiency; $(1 / 2)\left(\left|\mu_{\vec{A}}^{L}\left(x_{i}\right)-\nu_{\vec{A}}^{L}\left(x_{i}\right)\right|+\left|\mu_{\vec{A}}^{U}\left(x_{i}\right)-v_{\vec{A}}^{U}\left(x_{i}\right)\right|\right)$ is the interval distance of the degree of membership; $\left(\pi \frac{L}{A}\left(x_{i}\right)+\right.$ $\left.\pi \underset{A}{U}\left(x_{i}\right)\right) / 2$ is the average value of the maximum degree of membership and the minimum degree of membership, as well as the level of information insufficiency; and $e$ is the base of natural logarithms.

Based on improved interval intuitionistic fuzzy entropy formula (7), entropy matrix $E$ is built on the basis of the group integrated weighted interval-valued intuitionistic fuzzy judgment matrix:

$$
E=\left[\begin{array}{cccc}
e_{11} & e_{12} & \cdots & e_{1 n} \\
e_{21} & e_{22} & \cdots & e_{2 n} \\
\vdots & \vdots & \ddots & \vdots \\
e_{m 1} & e_{m 2} & \cdots & e_{m n}
\end{array}\right]
$$

After normalization, the standard entropy matrix is built as $\bar{E}$ : 


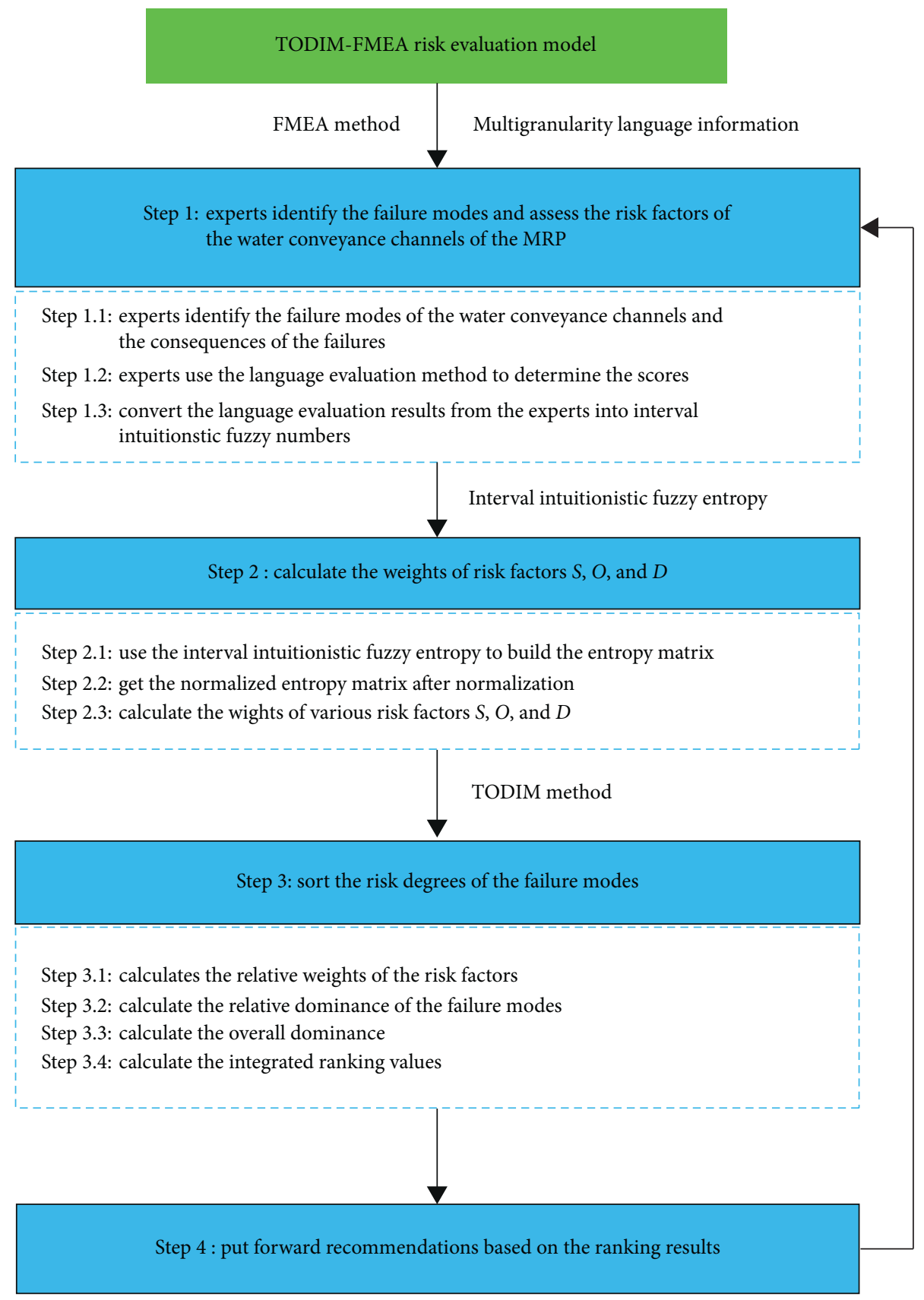

FIGURE 3: Risk assessment framework with TODIM-FMEA for the MRP.

where

$$
\bar{E}=\left[\begin{array}{cccc}
\bar{e}_{11} & \bar{e}_{12} & \cdots & \bar{e}_{1 n} \\
\bar{e}_{21} & \bar{e}_{22} & \cdots & \bar{e}_{2 n} \\
\vdots & \vdots & \ddots & \vdots \\
\bar{e}_{m 1} & \bar{e}_{m 2} & \cdots & \bar{e}_{m n}
\end{array}\right]
$$

Based on the standard entropy matrix $\bar{E}$, the weights of risk factors $S, O$, and $D$ can be obtained through the following formula:

$$
w_{i}=\frac{1-\sum_{i=1}^{m} \bar{e}_{i j}}{\sum_{j=1}^{n}\left(1-\sum_{i=1}^{m} \bar{e}_{i j}\right)} .
$$

$$
\bar{e}_{i j}=\frac{e_{i j}}{\max \left\{e_{1}, e_{2}, \ldots, e_{m j}\right\}}, \quad(i=1,2, \ldots, m, j=1,2, \ldots, n)
$$

Step 3: the TODIM method is used to rank the failure modes.

The classical TODIM approach is extended to a multigranularity language environment for 
calculation. The above steps have converted the multigranularity language information into interval intuitionistic fuzzy numbers, and then the integrated ranking of each failure mode is calculated according to the TODIM method. The detailed calculation steps are as follows.

(1) Calculate the relative weights of the risk factors:

The improved interval intuitionistic fuzzy entropy determined the weights of various indicators as $W=$ $\left(w_{1}, w_{2}, \ldots, w_{n}\right)$ and the relative weights as $W_{j}^{\prime}=\left(w_{1}^{\prime}, w_{2}^{\prime}, \ldots, w_{n}^{\prime}\right)$. The reference weights $w^{*}=$ $\max \left\{w_{1}, w_{2}, \ldots, w_{n}\right\}$ can be determined based on the following formula:

$$
w_{j}^{\prime}=\frac{w_{j}}{w^{*}}
$$

(2) Calculate the relative dominance as formula (12):

$$
\Phi_{j}\left(\mathrm{FM}_{i}, \mathrm{FM}_{P}\right)= \begin{cases}\sqrt{\frac{w_{j}^{\prime}}{\sum_{j=1}^{n} w_{j}^{\prime}} d\left(m_{i j}, m_{p j}\right),} & m_{i j}>m_{p j}, \\ 0, & m_{i j}=m_{p j}, \\ -(1 / \theta) \sqrt{\frac{\sum_{j=1}^{n} w_{j}^{\prime}}{w_{j}^{\prime}} d\left(m_{i j}, m_{p j}\right),} & m_{i j}<m_{p j},\end{cases}
$$

where $\theta$ is the loss attenuation coefficient; $\theta>1$ indicates that the influence of the loss will decrease, and $\theta<1$ indicates that the influence of the loss will increase. $d\left(m_{i j}, m_{p j}\right)$ indicates the distance between two interval intuitionistic fuzzy numbers, which is calculated with formula (5).

(3) Calculate the overall dominance and values of overall ranking:

The overall dominance can be determined from the following formula:

$$
\delta\left(\mathrm{FM}_{i}, \mathrm{FM}_{p}\right)=\sum_{j=1}^{n} \Phi_{j}\left(\mathrm{FM}_{i}, \mathrm{FM}_{p}\right)
$$

Values of overall ranking can be determined from the following formula:

$$
\zeta_{i}=\frac{\sum_{k=1}^{m} \delta\left(\mathrm{FM}_{i}, \mathrm{FM}_{p}\right)-\min _{i} \sum_{k=1}^{m} \delta\left(\mathrm{FM}_{i}, \mathrm{FM}_{p}\right)}{\max _{i} \sum_{k=1}^{m} \delta\left(\mathrm{FM}_{i}, \mathrm{FM}_{p}\right)-\min _{i} \sum_{k=1}^{m} \delta\left(\mathrm{FM}_{i}, \mathrm{FM}_{p}\right)}
$$

(4) The failure modes are ranked according to the values of $\zeta_{i}$.

\section{Case Analysis}

4.1. Case Description. This study takes the water channel of the Huixian section of the MRP as an example to analyze the operation risk. The Huixian section is located within Huixian City, Henan Province. The total length of the channel section is $48.951 \mathrm{~km}$, with $43.631 \mathrm{~km}$ of the open channel and $5.320 \mathrm{~km}$ of the hydraulic structure. Huixian city has a warm temperate continental monsoon climate. In spring, it is windy and lacks rain; in summer, it is rainy and hot; in autumn, it is cool; and in winter, it is quite cold and lacks snow. The annual precipitation varies greatly. The average precipitation varies greatly depending on the month and season. While the average annual precipitation is $589.1 \mathrm{~mm}$, the month of July sees nearly one-third of the total yearly precipitation, with an average of $182.3 \mathrm{~mm}$. The foundation of the channel section contains both weak expansive soil and collapsible loess. The collapsible loess section of the foundation was treated by dynamic compaction during construction.

4.2. Processes of Operation Risk Assessment. This section attempts to validate the effectiveness of the proposed TODIM-FMEA model based on multigranularity language variables to assess the operation risks of the water channel in the MRP.

Step 1: firstly, the FMEA expert team comprises three experts who are engaged in the field of operation management for the South-to-North Water Diversion Project, and they are a scientific research expert, an engineering design expert, and an operation management expert. The expert weights are assigned to them according to their different knowledge structures and field experience, which are denoted as $W=(0.28,0.31,0.41)$. The experts selected three different language granularities, 5, 7, and 9, respectively, based on their own preference for carrying out the assessment. The experts assessed the six failure modes using three risk factors, i.e., severity $(S)$, occurrence $(O)$, and detection difficulty $(D)$ with linguistic information, as shown in Table 2.

The multigranularity language evaluation sets are denoted as

$$
\begin{aligned}
& E: S^{5}=\left\{s_{-2}^{5}, s_{-1}^{5}, s_{0}^{5}, s_{1}^{5}, s_{2}^{5}\right\} \\
& E: S^{7}=\left\{s_{-3}^{7}, s_{-2}^{7}, s_{-1}^{7}, s_{0}^{7}, s_{1}^{7}, s_{2}^{7}, s_{3}^{7}\right\} \\
& E: S^{9}=\left\{s_{-4}^{9}, s_{-3}^{9}, s_{-2}^{9}, s_{-1}^{9}, s_{0}^{9}, s_{1}^{9}, s_{2}^{9}, s_{3}^{9}, s_{4}^{9}\right\} .
\end{aligned}
$$

Scoring rules: scoring from the three different granular language variables, i.e., 5, 7, and 9, is listed as follows: 
TABLE 2: Statistical table of the experts' evaluation information.

\begin{tabular}{lccccccccc}
\hline Experts & & $E 1$ & & \multicolumn{3}{c}{$E 2$} & & & \\
FMs & $S$ & $O$ & $D$ & $S$ & $O$ & $D$ & $S$ & $O$ & $D$ \\
\hline FM1 & $s_{0}^{5}$ & $s_{1}^{5}$ & $s_{-2}^{5}$ & $s_{0}^{7}$ & $s_{2}^{7}$ & $s_{-2}^{7}$ & $s_{1}^{9}$ & $s_{2}^{9}$ & $s_{-3}^{9}$ \\
FM2 & $s_{1}^{5}$ & $s_{-1}^{5}$ & $s_{-1}^{5}$ & $s_{1}^{7}$ & $s_{-2}^{7}$ & $s_{-3}^{7}$ & $s_{2}^{9}$ & $s_{-2}^{9}$ & $s_{-3}^{9}$ \\
FM3 & $s_{2}^{5}$ & $s_{-2}^{5}$ & $s_{1}^{5}$ & $s_{3}^{7}$ & $s_{-1}^{7}$ & $s_{-3}^{7}$ & $s_{3}^{9}$ & $s_{-3}^{9}$ & $s_{-1}^{9}$ \\
FM4 & $s_{0}^{5}$ & $s_{1}^{5}$ & $s_{0}^{5}$ & $s_{0}^{7}$ & $s_{0}^{7}$ & $s_{0}^{7}$ & $s_{-1}^{9}$ & $s_{3}^{9}$ & $s_{1}^{9}$ \\
FM5 & $s_{1}^{5}$ & $s_{0}^{5}$ & $s_{1}^{5}$ & $s_{2}^{7}$ & $s_{-1}^{7}$ & $s_{3}^{7}$ & $s_{3}^{9}$ & $s_{-1}^{9}$ & $s_{2}^{9}$ \\
FM6 & $s_{1}^{5}$ & $s_{-1}^{5}$ & $s_{0}^{5}$ & $s_{3}^{7}$ & $s_{-2}^{7}$ & $s_{2}^{7}$ & $s_{2}^{9}$ & $s_{-1}^{9}$ & $s_{1}^{9}$ \\
\hline
\end{tabular}

$S^{5}=\left\{s_{-2}^{5}=\right.$ Lowest $, \ldots, s_{0}^{5}=$ Medium, $\ldots, s_{2}^{5}=$ Highest $\}$,

$S^{7}=\left\{s_{-3}^{7}=\right.$ Lowest $, \ldots, s_{0}^{7}=$ Medium, $\ldots, s_{3}^{7}=$ Highest $\}$,

$S^{9}=\left\{s_{-4}^{9}=\right.$ Lowest $, \ldots, s_{0}^{9}=$ Medium, $\ldots, s_{4}^{9}=$ Highest $\}$.

The language evaluation information is converted into the corresponding interval intuitionistic fuzzy number. And interval intuitionistic fuzzy evaluation matrix $R$ is formed for the failure mode, as shown in Table 3 . Then, according to Definition 7, each expert's evaluation information is integrated using the interval-valued intuitionistic fuzzy weighted arithmetic averaging (IIWAA) operator. Finally, the group integrated weight of interval-valued intuitionistic fuzzy judgment matrix $R^{\prime}=\left[a_{i j}\right]_{m \times n}$ is obtained, as shown in Table 4.

Step 2: the weights are calculated based on interval intuitionistic fuzzy entropy. Firstly, the entropy value of the group integrated weight of interval-valued intuitionistic fuzzy judgment matrix is calculated. According to improved interval intuitionistic fuzzy entropy formula (7), the matrix is calculated as follows:

$$
E=\left[\begin{array}{lll}
0.4581 & 0.2524 & 0.1142 \\
0.2824 & 0.1742 & 0.1355 \\
0.1884 & 0.1608 & 0.4776 \\
0.3354 & 0.3000 & 0.4581 \\
0.2261 & 0.3794 & 0.2322 \\
0.2322 & 0.2420 & 0.3421
\end{array}\right] .
$$

Then, the elements in the entropy matrix are normalized, and normalized entropy matrix $\bar{E}$ is built:

$$
\bar{E}=\left[\begin{array}{lll}
1.0000 & 0.6652 & 0.2391 \\
0.6165 & 0.4593 & 0.2837 \\
0.4112 & 0.4239 & 1.0000 \\
0.7321 & 0.7908 & 0.9592 \\
0.4935 & 1.0000 & 0.4862 \\
0.5069 & 0.6379 & 0.7163
\end{array}\right] .
$$

Based on normalized entropy matrix $\bar{E}$, the weights of risk factors $S, O$, and $D$ can be calculated through formula (11): $W_{i}=(0.3277,0.3535,0.3188)$.

Step 3: ranking failure modes of the water channels in the MRP with the TODIM method.

(1) According to formula (12), relative weights of the risk factors are calculated as $W_{j}^{\prime}=(0.9272$, $1.0000,0.9018)$.

(2) Calculate the relative dominance.

As to the relative dominance, the decision maker's judgment is largely determined by the size of the loss attenuation coefficient $\theta$, and $\theta$ is negatively correlated with the decision maker's degree of loss avoidance. When $\theta>1$, it indicates that the impact of the loss will decrease and that the decision maker holds an attitude of risk aversion; when $\theta<1$, it indicates that the impact of the loss will increase and that the decision maker holds an attitude of willingness to confront risks. If $\theta=1$ is adopted, it indicates the decision maker holds a neutral attitude to risks. The distance is obtained through formula (5), and the relative dominance $\phi$ of the risk factors $S, O$, and $D$ under different failure modes is determined through a pairwise comparison of the failure modes according to formula (13). The dominance matrix $\phi_{c}=\left[\phi_{i j}\right]_{m \times m}$ is generated, as shown in Table 5 .

(3) Calculate the overall dominance matrix and integrated ranking values.

In accordance with formula (14), the overall dominance matrix $\delta=\left[\delta_{i j}\right]_{m \times m}$ can be derived, as shown in Table 6.

According to formula (15), the integrated ranking values of the risk levels of the six failure modes are $\zeta_{1}=0.0459 ; \zeta_{2}=0 ; \zeta_{3}=0.6035 ; \zeta_{4}=0.5227 ; \zeta_{5}=1$; $\zeta_{6}=0.7825$.

(4) Rank the failure modes.

Based on the overall dominance, the integrated sequence of $\zeta_{i}$ is ranked according to the values. The ranking result is $\zeta_{5}>\zeta_{6}>\zeta_{3}>\zeta_{4}>\zeta_{1}>\zeta_{2}$. According to the ranking, abnormal leakage (FM6) poses the largest riesk, and the poor water delivery during ice periods poses the lowest level. The ranking result is shown in Figure 4.

According to the radar diagram in Figure 4, abnormal leakage is the most typical failure mode in the risk identification of the water channels in the MRP. Abnormal leakage will not only cause a loss of water quantity but, more seriously, will also cause erosion to the foundation and bank slopes, which will endanger the overall stability of the structures. Cracks and leakage will reduce material strength, thus accelerating crack development and leading to a vicious circle of deterioration. Therefore, abnormal leakage has an important effect on the safety of the water channels in the MRP. The failure mode of 


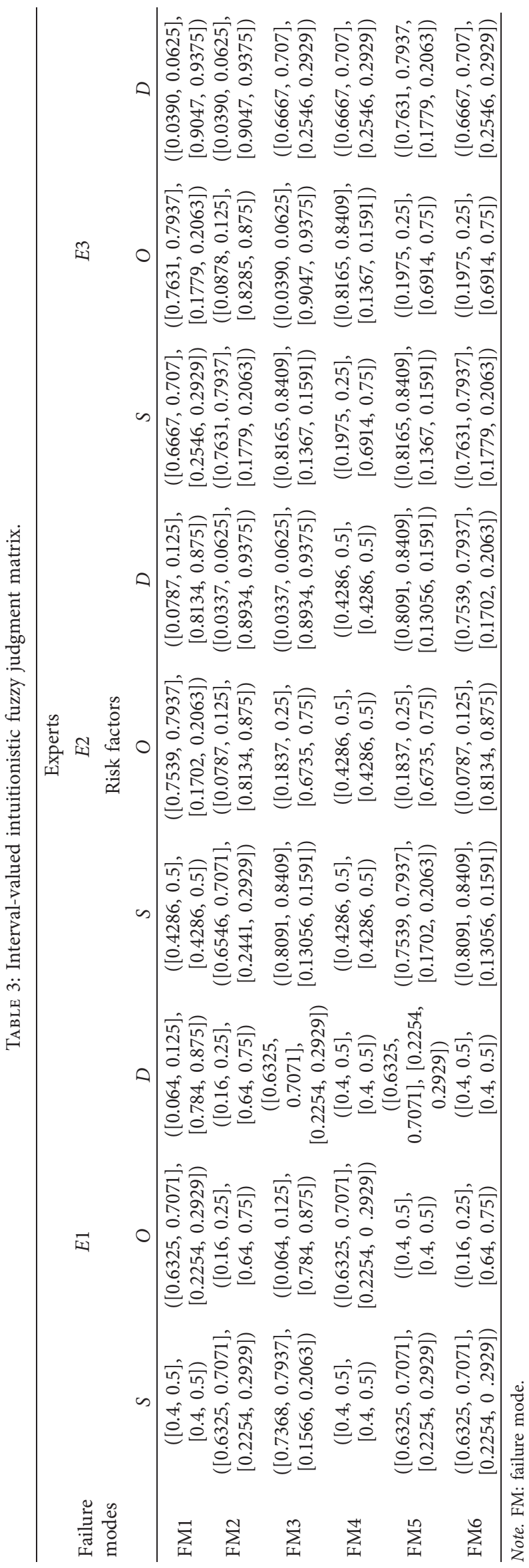




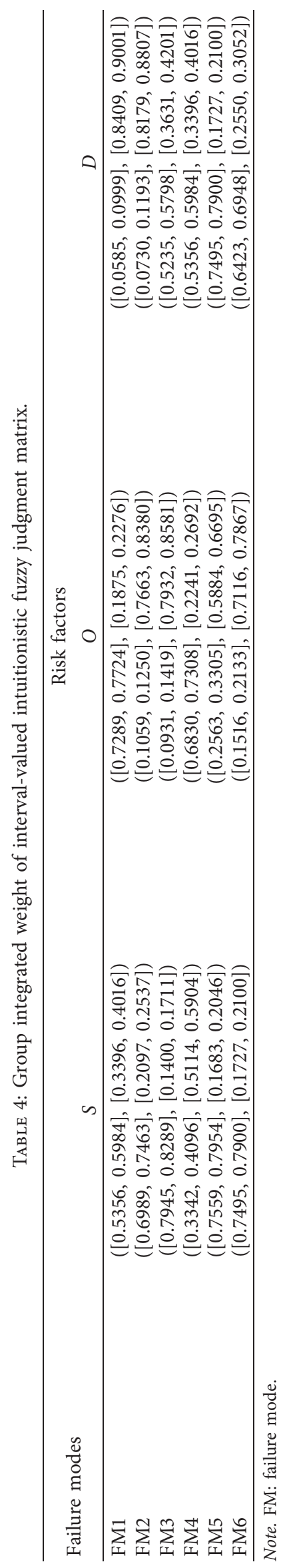




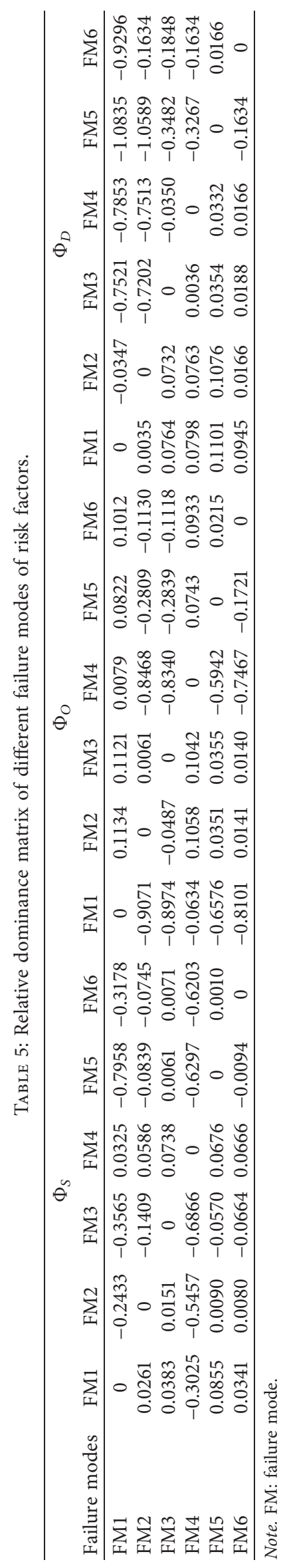


TABLE 6: Overall dominance matrix.

\begin{tabular}{lcccccc}
\hline$\delta$ & FM1 & FM2 & FM3 & FM4 & FM5 & FM6 \\
\hline FM1 & 0 & -0.1646 & -0.9964 & -0.7449 & -1.7972 & -1.1462 \\
FM2 & -0.8775 & 0 & -0.8550 & -1.5394 & -1.4237 & -0.3509 \\
FM3 & -0.7827 & 0.0396 & 0 & -0.7953 & -0.6260 & -0.2895 \\
FM4 & -0.2861 & -0.3636 & -0.5788 & 0 & -0.8821 & -0.6903 \\
FM5 & -0.4620 & 0.1517 & 0.0139 & -0.4934 & 0 & 0.0391 \\
FM6 & -0.6815 & 0.0387 & -0.0336 & -0.6635 & -0.3449 & 0 \\
\hline
\end{tabular}

Note. FM: failure mode.

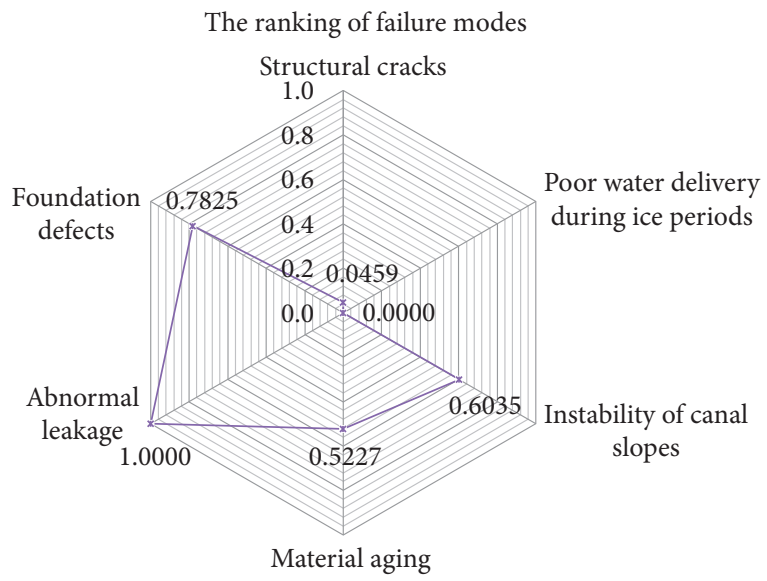

FIgURE 4: The ranking of six failure modes.

foundation defects poses the second largest threat. There is weak expansive soil in the Huixian section of the water channels in the MRP. Over the course of the operation, we should strengthen inspections of the geological risks and take engineering measures to reduce those risks in a timely manner when problems arise. Although the failure modes of structural cracks, instability of canal slopes, and material aging rank behind abnormal leakage and foundation defects, they are important failure modes as well for the safe operation of the channels in the MRP. Over the course of operation, some concrete measures should be put forward to improve and enhance the reliability of the water channels in the MRP. Poor water conveyance during ice periods poses the least risk because Huixian county is at a low latitude, and it will experience less harm to water delivery during ice periods in winter than northern regions will.

4.3. Comparison and Discussion. In this case, the two methods, i.e., interval intuitionistic fuzzy set TOPSIS and traditional RPN, were used to analyze risks, and the results were compared with those of the TODIM method, as shown in Table 7 . The ranking results of the three methods are very similar, and the ranking of failure modes FM5 and FM2 is the same. That is, all methods ranked FM5 as the most serious failure mode and FM2 as the least serious failure mode, which shows that the three methods are all valid.
TABLE 7: Ranking comparison result.

\begin{tabular}{lcccccc}
\hline $\begin{array}{l}\text { Failure } \\
\text { mode }\end{array}$ & \multicolumn{2}{c}{ RPN } & \multicolumn{2}{c}{ TOPSIS } & \multicolumn{2}{c}{ TODIM } \\
\hline FM1 & RPN & Ranking & RCC & Ranking & $\delta$ & Ranking \\
FM2 & 71.5856 & 4 & 0.6145 & 3 & 0.0459 & 5 \\
FM3 & 103.0053 & 6 & 0.0022 & 6 & 0.0000 & 6 \\
FM4 & 245.9878 & 2 & 0.3003 & 5 & 0.6035 & 3 \\
FM5 & 352.8724 & 1 & 0.4135 & 4 & 0.5227 & 4 \\
FM6 & 222.4502 & 3 & 0.8903 & 2 & 0.7825 & 2 \\
\hline
\end{tabular}

Note. FM: failure mode.

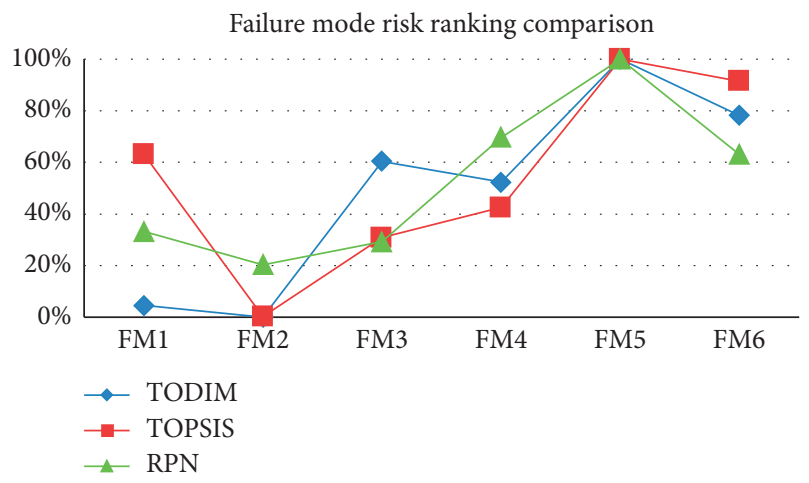

FIGURE 5: Failure mode risk ranking comparison.

While the comparison between the TODIM method and the TOPSIS method shows there is positional ranking crossing over for FM1 and FM3, the risk ranking of the remaining four failure modes is the same, which proves the effectiveness of the multigranularity language evaluation TODIM method.

Figure 5 depicts deviations of the failure modes with the most severe failure mode for each ranking method. In Figure 5, it can be seen that the fluctuation forms of the three methods are basically the same. The difference in risk identification results between TODIM and TOPSIS is due to the TODIM method taking into consideration the decision makers' psychological behavior and risk preference. Therefore, the multigranularity language TODIM method is more reliable than the traditional RPN method and the TOPSIS method.

The ranking of the improved FMEA risk evaluation approach differs from other approaches, and the reasons can be explained as follows:

(1) The calculation of the proposed model is based on multigranularity language variables. Experts can more accurately evaluate the FMEA failure modes with multigranularity language variables, which are converted into interval direct fuzzy numbers. The multigranularity language variables can quantitatively explain the evaluation results from experts.

(2) The traditional RPN calculation does not assign weights to risk factors $S, O$, and $D$. The proposed model adopted improved interval intuition entropy to assign weights to the risk factors, which can 
determine the influence of risk factors in the evaluation process.

(3) The TODIM method proposed in this paper fully considers the psychological behaviors of experts, but the TOPSIS method assumes that experts are absolutely rational people. For the TODIM method, a pairwise comparison of all failure modes uses relative dominance to determine the overall dominance ranking. This causes the results to contain more information. It is found that the FMEA risk evaluation method based on multigranularity language TODIM can more accurately reflect the opinions of experts and more accurately obtain the relationship between various failure modes.

\section{Conclusions}

Channel engineering is one of the most important parts of system engineering in the MRP. This paper proposed a new FMEA risk evaluation model based on the multigranularity language information TODIM method. The multigranularity language, which can be converted into intervalvalued intuition fuzzy sets, is used to evaluate the engineering failure modes. The degree of membership and the degree of nonmembership are used to express the decision maker's psychology of hesitation and quantify the risks. The weights of the risk factors, severity $(S)$, occurrence $(O)$, and detection difficulty $(D)$, are calculated by using improved interval intuitionistic fuzzy entropy. The risk assessment model is built based on the TODIM-FMEA method. Finally, a case study of the Huixian section of the MRP is presented. The results show that abnormal leakage is the most risky failure mode. A comparison of three risk ranking methods shows that the proposed model is more effective than the traditional RPN method and the TOPSIS method.

The TODIM-FMEA risk evaluation model with multigranularity language is highly operational and quite practical, providing a new solution to the problem of operational safety risk evaluation in water conservancy projects. The limitation of this study is that the weights of experts were directly assigned, which may lead to a deviation in risk ranking results. Therefore, in the future, appropriate methods can be studied for calculating the weights of experts to optimize the risk assessment model.

Some suggestions should be put forward to control the operation risks of water channels in the MRP. From the perspective of engineering safety, once leakage is found, or the values of deformations and cracks prompt warnings from the structure monitoring system of the MRP, it is necessary to quickly and accurately find the source of the leakage to eliminate defects and damage from the leakage and to prevent defects or damage from expanding. From the perspective of water delivery, it is necessary to reduce the impact on dispatching and operation as much as possible. It is necessary to carry out underwater repair research to optimize underwater construction techniques.

\section{Notations}

FMEA: $\quad$ Failure Mode and Effects Analysis

RPN: $\quad$ Risk priority number

SNWDP: The South-to-North Water Diversion Project

ERP: The East Route Project

MRP: The Middle Route Project

WRP: The West Route Project

TOPSIS: Technique for Order Preference by Similarity to Ideal Solution

S: $\quad$ Severity

$O: \quad$ Occurrence

D: $\quad$ Detection difficulty

DEMATEL: Decision-Making Trial and Evaluation Laboratory

TODIM: Tomada de Decisão Interativa Multicritério

IIWAA: The interval-valued intuitionistic fuzzy weighted arithmetic averaging.

\section{Data Availability}

The data used to support the findings of this study are available from the corresponding author upon request.

\section{Conflicts of Interest}

The authors declare that they have no conflicts of interest.

\section{Acknowledgments}

The authors acknowledge with gratitude the National Key R\&D Program of China (no. 2018YFC0406905), MOE (Ministry of Education in China) Project of Humanities and Social Sciences (no. 19YJC630078), Henan Overseas Expertise Introduction Center for Discipline Innovation: Smart Water, Youth Talents Teachers Scheme of Henan Province Universities (no. 2018GGJS080), the National Natural Science Foundation of China (nos. 71974056 and 71302191), the Foundation for Distinguished Young Talents in Higher Education of Henan (Humanities and Social Sciences), China (no. 2017-cxrc-023), the China Scholarship Council (no. 201908410388), and 2018 Henan Province Water Conservancy Science and Technology Project (GG201828). This study would not have been possible without their financial support.

\section{References}

[1] Office of the South-to-North Water Diversion Project Construction Committee, "The South-to-North Water Diversion Project," Engineering, vol. 2, no. 3, pp. 265-267, 2016.

[2] Z. Luo, S. Li, K. Hou, and G. Ji, "Spatial and seasonal bacterioplankton community dynamics in the main channel of the middle route of South-to-North Water diversion project," Research in Microbiology, vol. 170, no. 1, pp. 24-34, 2019.

[3] H. Shen, Q. Cai, and M. Zhang, "Spatial gradient and seasonal variation of trophic status in a large water supply reservoir for the South-to-North Water Diversion Project, China," Journal of Freshwater Ecology, vol. 30, no. 2, pp. 249-261, 2015. 
[4] C. Tang, Y. Yi, Z. Yang, and X. Cheng, "Water pollution risk simulation and prediction in the main canal of the South-toNorth Water Transfer Project," Journal of Hydrology, vol. 519, pp. 2111-2120, 2014

[5] S. Li, J. Li, and Q. Zhang, "Water quality assessment in the rivers along the water conveyance system of the Middle Route of the South to North Water Transfer Project (China) using multivariate statistical techniques and receptor modeling," Journal of Hazardous Materials, vol. 195, pp. 306-317, 2011.

[6] X. Lei, H. Zheng, and L. Kong, "Emergency operation technologies for sudden water pollution accidents," in Emergency operation technologies for sudden water pollution accidents in the middle route of south-to-north water diversion project, pp. 1-8, L. Xiaohui, IntechOpen Publisher, London, UK, 2018.

[7] X. Du and L. Geng, "Risk analysis on operation of mid-route of South-to-North Water transfer project," Water Resources and Hydropower Engineering, vol. 42, no. 3, pp. 85-88, 2011.

[8] D. Hu, L. Zheng, S. Li, and G. Shi, "Study on the risk evaluation method for the open channel operation in the middle route of South-to-North Water diversion project," South-tonorth Water Transfer and Water Science and Technology, vol. 11, no. 6, pp. 98-101, 2013.

[9] W. Cheng, J. Chen, and T. Liu, "Method for computing correlation coefficient between structural risks in water transfer project," Journal of Wuhan University of Hydraulic and Electric Engineering, no. 1, pp. 15-18, 2004.

[10] M. Zhou, J. Lian, X. Cheng, and X. Zhao, "Study on measures for main canal operation of middle route project of South-toNorth Water diversion during ice period," Yangtze River, vol. 47, no. 21, p. 106, 2016.

[11] Y. Xiong, W. Qi, and Z. Wang, "Operation risk study on the middle route of the South-to North Water diversion project (part I) -risk identification in the middle route of the Southto-North water diversion project," South-to-North Water Transfers and Water Science and Technology, vol. 8, no. 3, pp. 1-5, 2010.

[12] V. R. Renjith, M. Jose kalathil, P. H. Kumar, and D. Madhavan, "Fuzzy FMECA (failure mode effect and criticality analysis) of LNG storage facility," Journal of Loss Prevention in the Process Industries, vol. 56, pp. 537-547, 2018.

[13] I. Lazakis, Y. Raptodimos, and T. Varelas, "Predicting ship machinery system condition through analytical reliability tools and artificial neural networks," Ocean Engineering, vol. 152, pp. 404-415, 2018.

[14] W. Choi, B. D. Youn, H. Oh, and N. H. Kim, "A Bayesian approach for a damage growth model using sporadically measured and heterogeneous on-site data from a steam turbine," Reliability Engineering \& System Safety, vol. 184, pp. 137-150, 2019.

[15] K. Chang, "A more general risk assessment methodology using a soft set-based ranking technique," Soft Computing, vol. 18, no. 1, pp. 169-183, 2014.

[16] B. Vahdani, M. Salimi, and M. Charkhchian, "A new FMEA method by integrating fuzzy belief structure and TOPSIS to improve risk evaluation process," The International Journal of Advanced Manufacturing Technology, vol. 77, no. 1-4, pp. 357-368, 2015.

[17] R. Wang, J. Zhu, and Y. Li, "Improved FMEA risk assessment method based on intuitionistic fuzzy MULTIMOORA," Computer Integrated Manufacturing System, vol. 24, no. 2, pp. 290-301, 2018.

[18] I. Emovon, R. A. Norman, A. J. Murphy, and K. Pazouki, “An integrated multicriteria decision making methodology using compromise solution methods for prioritising risk of marine machinery systems," Ocean Engineering, vol. 105, pp. 92-103, 2015.

[19] J. Zhu, G. Li, R. Wang, and Y. Li, "FMEA based assessment of risk that metro train stops abnormally," China Safety Science Journal, vol. 27, no. 2, pp. 145-150, 2017.

[20] H.-C. Liu, J.-X. You, M.-M. Shan, and L.-N. Shao, "Failure mode and effects analysis using intuitionistic fuzzy hybrid TOPSIS approach," Soft Computing, vol. 19, no. 4, pp. 1085-1098, 2015.

[21] K.-H. Chang, Y.-C. Chang, and Y.-T. Lee, "Integrating TOPSIS and DEMATEL methods to rank the risk of failure of FMEA," International Journal of Information Technology and Decision Making, vol. 13, no. 06, pp. 1229-1257, 2014.

[22] L. Gomes and M. Lima, "TODIM: basics and application to multicriteria ranking of projects with environmental impacts," Foundations of Computing and Decision Sciences, vol. 16, no. 4, pp. 113-127, 1992.

[23] K. T. Atanassov, "Two theorems for intuitionistic fuzzy sets," Fuzzy Sets and Systems, vol. 110, no. 2, pp. 267-269, 2000.

[24] E. Szmidt and J. Kacprzyk, "Distances between intuitionistic fuzzy sets," Fuzzy Sets and Systems, vol. 114, no. 3, pp. $505-518,2000$.

[25] M. Delgado, F. Herrera, E. Herrera-Viedma, and L. Martinez, "Combining numerical and linguistic information in group decision making," Information Sciences, vol. 107, no. 1-4, pp. 177-194, 1998.

[26] Z. Xu and J. Chen, "Approach to group decision making based on interval-valued intuitionistic judgment matrices," Systems Engineering-Theory \& Practice, vol. 27, no. 4, pp. 126-133, 2007. 